\title{
Indução de perda de massa na qualidade pós-colheita de pêssegos 'Eragil’ em armazenamento refrigerado
}

\author{
Induction of mass loss in post-harvest quality of 'Eragil' peaches in cold storage \\ Josuel Alfredo Vilela Pinto ${ }^{I}$ Auri Brackmann ${ }^{\text {II }}$ Márcio Renan Weber Schorr ${ }^{\text {III }}$ \\ Thiago Liberalesso Venturini ${ }^{\mathrm{V}}$ Fabio Rodrigo Thewes ${ }^{\mathrm{V}}$
}

\section{RESUMO}

O objetivo deste trabalho foi avaliar a indução de perda de massa fresca na qualidade pós-colheita de pêssegos 'Eragil' após 21 dias de armazenamento a $-0,5^{\circ} \mathrm{C}$. Utilizou-se o delineamento inteiramente casualizado com cinco repetições de 20 frutos. Foram avaliados 4, 5, 6 e 7\% de perda de massa fresca induzida. A incidência de lanosidade aumenta com o aumento da perda de massa, dois dias após o armazenamento, mas não é afetada aos quatro dias a $20^{\circ} \mathrm{C}$. A suculência, aos dois dias e a produção de etileno, aos dois e quatro dias a $20^{\circ} \mathrm{C}$ possuem relação inversa com a perda de massa. A firmeza de polpa foi mantida e a respiração aumentada com maior perda de massa aos dois dias a $20^{\circ} \mathrm{C} .5$ a $6 \%$ de perda de massa proporciona menor evolução da coloração amarela. Portanto, pêssegos 'Eragil' são susceptíveis à ocorrência de lanosidade após 21 dias a $-0,5^{\circ} \mathrm{C}$, sendo este processo revertido a $20^{\circ} \mathrm{C}$. O aumento na perda de massa fresca promove aumento na firmeza de polpa, lanosidade, SST e respiração, e redução na suculência, produção de etileno e atividade da enzima ACC oxidase.

Palavras-chave: Prunus persica, etileno, lanosidade.

\section{ABSTRACT}

The aim of this study was to evaluate the induction of mass loss in the post-harvest quality of 'Eragil' peaches after 21 days cold storage at $-0.5^{\circ} \mathrm{C}$. Was used completely randomized design with five replications of 20 fruits. Were evaluated 4, 5, 6 e $7 \%$ of mass loss induced. Woolliness incidence increase with rise in mass loss, two days after storage, but is not affected four days at $20^{\circ} \mathrm{C}$. Juiciness, in second day, and ethylene production, in second and fourth days at $20^{\circ} \mathrm{C}$, are inversely relationship to mass loss. Fruit firmness were remained and respiratory rate increased with greater mass loss two days at $20^{\circ} \mathrm{C}$. 5-6\% mass loss provided less evolution of yellow color. Therefore, 'Eragil' peaches are susceptible to wooliness occurrence after 21 days at $-0.5^{\circ} \mathrm{C}$, be this process reverted at $20^{\circ} \mathrm{C}$. The rise in mass loss promotes increase in fruit firmness, woolliness, TSS and respiratory rate, and decrease in juiciness, ethylene production and ACC oxidase enzyme activity.

Key words: Prunus persica, ethylene, woolliness.

\section{INTRODUÇÃO}

O cultivo de frutas de caroço (Prunus ssp.) possui importância econômica-social nos estados da região sul e sudeste do Brasil, principalmente no Rio Grande do Sul, responsável por mais de $60 \%$ da produção nacional (BARBOSA et al., 2010; OLIVEIRA et al., 2011). O volume da produção brasileira não atende a própria demanda, o que tem resultado em aumento na área plantada, principalmente de pêssegos para o consumo in natura (MADAIL \& RASEIRA, 2008) e duplo propósito.

Cultivares de duplo propósito têm sido muito utilizadas na instalação de pomares ou renovações dos já existentes, já que possibilitam tanto a venda in natura, o que agrega até $50 \%$ no valor do

IUniversidade Federal da Fronteira Sul (UFFS), Laranjeira do Sul, PR, Brasil.

${ }^{I I D}$ partamento de Fitotecnia, Universidade Federal de Santa Maria (UFSM), 97105-900, Santa Maria, RS, Brasil. E-mail: auribrackmann@gmail.com. Autor para correspondência.

IIIPrograma de Pós-graduação em Agronomia, UFSM, Santa Maria, RS, Brasil.

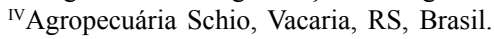

${ }^{\mathrm{v}}$ Curso de Agronomia, UFSM, Santa Maria, RS, Brasil. 
produto, quanto para a indústria, no caso de excedente de produção. Várias são as cultivares de duplo propósito desenvolvidas, dentre elas a 'Eragil', a qual tem ganho destaque devido suas características como: polpa amarela, tamanho grande e mais de $50 \%$ da epiderme com cor avermelhada (BRACKMANN et al., 2009).

O pêssego é um fruto climatérico e altamente perecível em pós-colheita, apresentando rápida perda de firmeza de polpa, incidência de podridões e murchamento (NAVA \& BRACKMANN, 2001). Além disso, a quantidade colhida dessa fruta não é prontamente absorvida pelo mercado consumidor, o que gera a necessidade de alternativas que mantêm a sua oferta por mais tempo, sendo o armazenamento em baixas temperaturas uma dessas alternativas.

$\mathrm{O}$ armazenamento refrigerado (AR) é o principal método utilizado na conservação de pêssegos. A redução da temperatura reduz drasticamente a respiração dos frutos, retardando o amadurecimento e, consequentemente, aumentando seu período de armazenamento. Aliado ao AR, pode-se utilizar outras técnicas como a absorção de etileno (BRACKMANN et al., 2001), atmosfera controlada (BRACKMANN et al., 2009) e controle da umidade relativa (UR) no interior da câmara.

O controle da UR dentro da câmara de armazenagem exerce grande influência na qualidade dos frutos, já que, quando alta (maior que 95\%), aumenta a incidência de podridões e rachaduras (SCHWARZ, 1994) e quando baixa (menor que 90\%), promove excessiva perda de água dos frutos causando visível murchamento, além de estimular a produção de etileno e respiração (YANG \& PRATT, 1978). O controle exato da UR durante a armazenagem não é uma tarefa fácil, pois pequenas variações na temperatura da câmara fazem com que varie também a UR, principalmente em baixas temperaturas, tornando-se muito instável nessas condições.

A perda de água dos frutos durante o período de armazenamento deve-se principalmente à transpiração (MAGUIRE et al, 2000) e está relacionada ao déficit de pressão entre estes e o ambiente. A indução da perda de massa fresca dos frutos, através da absorção de água do ambiente interno da câmara de armazenagem, torna possível o controle exato da transpiração e permite fazê-la de modo constante durante todo o período. Essa perda de água varia, dependendo da espécie e da UR e, além disso, não se tem na literatura uma correlação exata entre a UR no interior da câmara e a perda de massa dos frutos. Os autores NAVA \& BRACKMANN (2001), encontraram uma perda de massa de $6,1 \%$ em pêssegos mantidos durante quatro semanas em UR de $90 \%$ e $3-4 \%$ quando a U.R. manteve-se acima de $95 \%$.

Diante disso, realizou-se este trabalho com o objetivo de avaliar a indução de perda de massa fresca na manutenção da qualidade pós-colheita de pêssegos 'Eragil' durante armazenamento em atmosfera refrigerada.

\section{MATERIAL E MÉTODOS}

O experimento foi conduzido no Núcleo de Pesquisa em Pós-Colheita do Departamento de Fitotecnia da Universidade Federal de Santa Maria, RS, com frutos provenientes de um pomar comercial localizado no município de Antônio Prado, RS.

Os frutos, depois de homogeneizados, foram acondicionados em minicâmaras experimentais de $0,233 \mathrm{~m}^{3}$ cada, as quais encontravam-se no interior de uma câmara frigorífica com $45 \mathrm{~m}^{3}$. Os frutos foram armazenados em ambiente refrigerado (AR) durante 21 dias, na temperatura de $-0,5( \pm 0,5)^{\circ} \mathrm{C}$. A temperatura foi monitorada diariamente com termômetros de mercúrio (resolução de $0,2^{\circ} \mathrm{C}$ ). Devido à necessidade de as minicâmaras estarem hermeticamente fechadas, para que os tratamentos pudessem ser aplicados, a concentração de $\mathrm{O}$ foi mantida em aproximadamente $21,0 \mathrm{kPa}$, com injeçẫo de ar atmosférico quando ocorria consumo, devido à respiração dos frutos, e a concentração desejada de $\mathrm{CO}_{2}$ foi obtida com absorção com cal virgem do gás gerado pela respiração, durante todo o período.

O delineamento experimental utilizado foi o inteiramente casualizado, com cinco repetições de 20 frutos. Foram avaliados [T1] 4\%; [T2] 5\%; [T3] 6\% e [T4] 7\% de perda de massa fresca. A indução da perda de massa fresca foi realizada a cada quatro dias, através da passagem forçada do ar do interior da minicâmara por um recipiente contendo sílica gel, o qual retirava a umidade do ar.

Após 21 dias de armazenamento, os frutos foram avaliados aos dois e quatro dias de exposição a $20^{\circ} \mathrm{C}$. Os parâmetros avaliados foram: lanosidade, através de análise subjetiva, atribuindo-se 1 para fruto não lanoso, 2 para fruto mediamente lanoso e 3 para fruto totalmente lanoso, expresso em porcentagem; suculência, determinada através da prensagem de $20 \mathrm{~g}$ de polpa de frutos em uma prensa hidráulica $\left(15 \mathrm{~kg} \mathrm{~cm}^{-2}\right)$ durante um minuto, e expresso em porcentagem de suco livre; firmeza de polpa, com o uso de um penetrômetro com ponteira de 7,9mm de diâmetro, expressos em Newtons (N); acidez titulável, através da titulação com $\mathrm{NaOH} 0,1 \mathrm{~N}$ de $10 \mathrm{~mL}$ de suco do fruto diluídos em $100 \mathrm{~mL}$ de água destilada e deionizada até $\mathrm{pH}$ 8,1 e expressa 
em meq $100 \mathrm{~mL}^{-1}$; sólidos solúveis totais, determinados por refratometria e expressos em ${ }^{\circ}$ Brix; cor de fundo da epiderme, determinada com auxílio de um colorímetro, marca Minolta ${ }^{\circledR}$, expressa em Hue; produção de etileno, por cromatografia gasosa, determinada a produção do gás por uma massa de frutos em recipiente fechado com volume conhecido e durante um determinado período, expressa em $\mu \mathrm{LC}_{2} \mathrm{H}_{4} \mathrm{~kg}^{-1} \mathrm{~h}^{-1}$; respiração, obtida através da produção de $\mathrm{CO}_{2}$, determinada com um analisador eletrônico, da marca Agri-Datalog ${ }^{\circledR}$, também em função da massa de frutos, volume do recipiente e tempo de seu fechamento, expressa em $\mathrm{mLCO} \mathrm{kg}^{-1} \mathrm{~h}^{-1}$; e atividade da enzima ACC oxidase, determinada através da produção de etileno por porções de 3 gramas de epiderme deixadas em solução contendo ACC durante 30 minutos e, posteriormente, em uma seringa contendo $1 \%$ de $\mathrm{CO}_{2}$, por mais 30 minutos, expressa em $\mu \mathrm{LC}_{2} \mathrm{H}_{4} \mathrm{~g}^{-1} \mathrm{~h}^{-1}$.

Os dados expressos em porcentagem foram transformados pela fórmula arcsen $[(\mathrm{x}+0,5) / 100]^{1 / 2}$, antes da análise de variância. Foi utilizado o software estatístico SISVAR e os dados expressos na forma de regressões.

\section{RESULTADOS E DISCUSSÃO}

Antes do armazenamento refrigerado (AR), foi realizada uma análise para a determinação do estádio de maturação dos frutos (Figura 1). A produção de etileno e a respiração dos frutos, após a colheita, apresentaram aumento lento e gradual até o quinto dia e pico ao sexto. O pico climatérico é caracterizado por um aumento significativo na respiração dos frutos, induzido por um aumento na produção autocatalítica de etileno (RHODES, 1980). A suculência, firmeza de polpa, acidez titulável e Hue (coloração) apresentaram redução durante os sete dias, com a firmeza chegando a níveis muito baixos (menores que $10 \mathrm{~N}$ ) aos cinco e sete dias. A redução do Hue mostra a evolução da cor do verde ao amarelo. Os SST apresentaram uma leve redução logo após a colheita, devido à respiração, mas aumentou posteriormente, pela degradação das paredes celulares. A análise inicial é útil na identificação do padrão normal de amadurecimento, alterado pelo armazenamento refrigerado, e para estimar a vida de prateleira dos frutos.

Após 21 dias em AR mais dois dias a $20^{\circ} \mathrm{C}$, a incidência de lanosidade (Figura 2) foi representada por uma função de segundo grau e a curva que a explica possui concavidade voltada para cima. A maior incidência de lanosidade ocorreu com $7 \%$ de perda de massa, sendo 71,72 e $56 \%$ maior que com 4,5 e $6 \%$ de perda de massa, respectivamente. Já, aos quatro dias a $20^{\circ} \mathrm{C}$, não houve diferença estatística, sendo a média dos tratamentos $2,15 \%$. Segundo NAVA \&

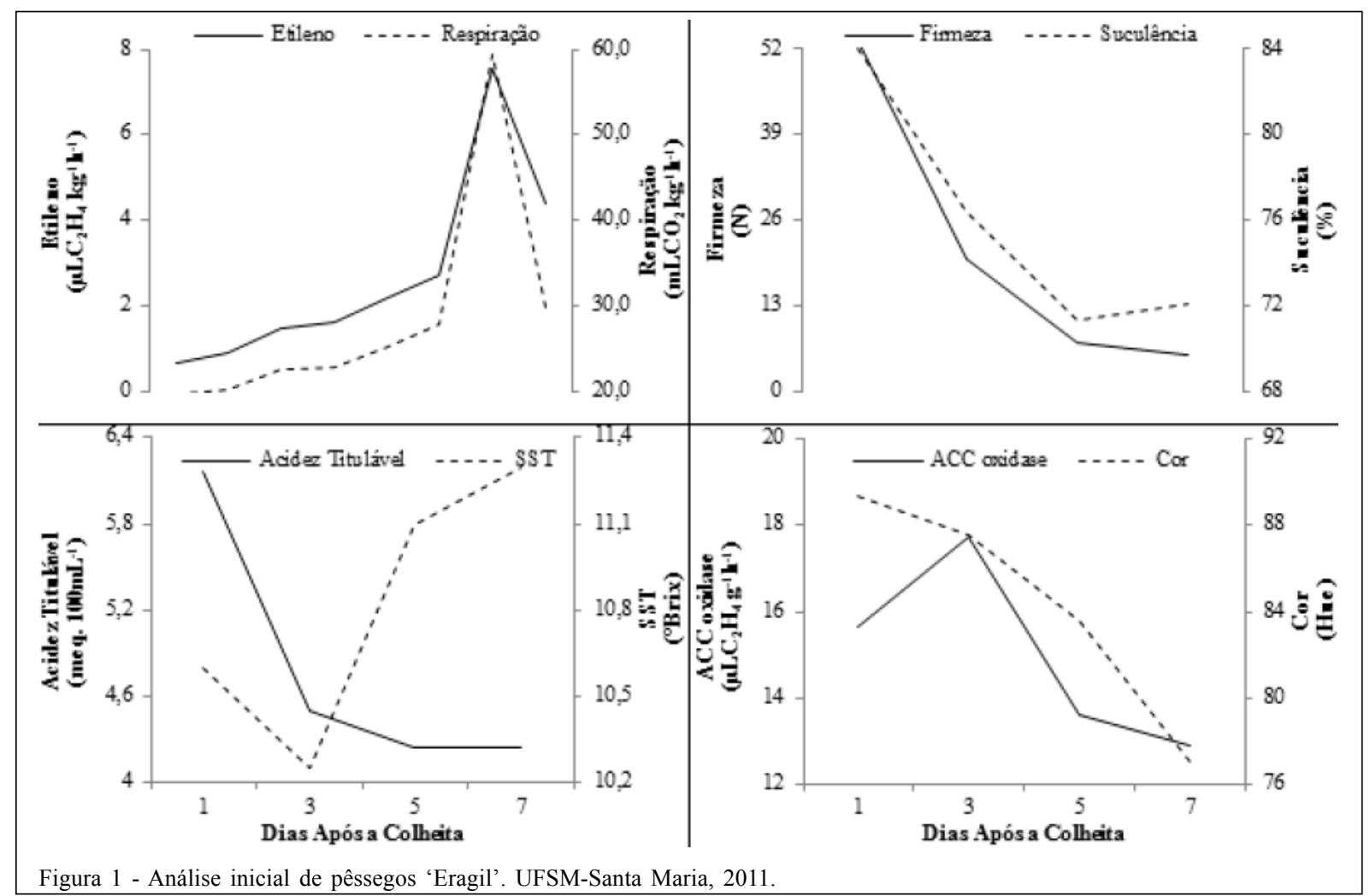

Ciência Rural, v.42, n.6, jun, 2012. 


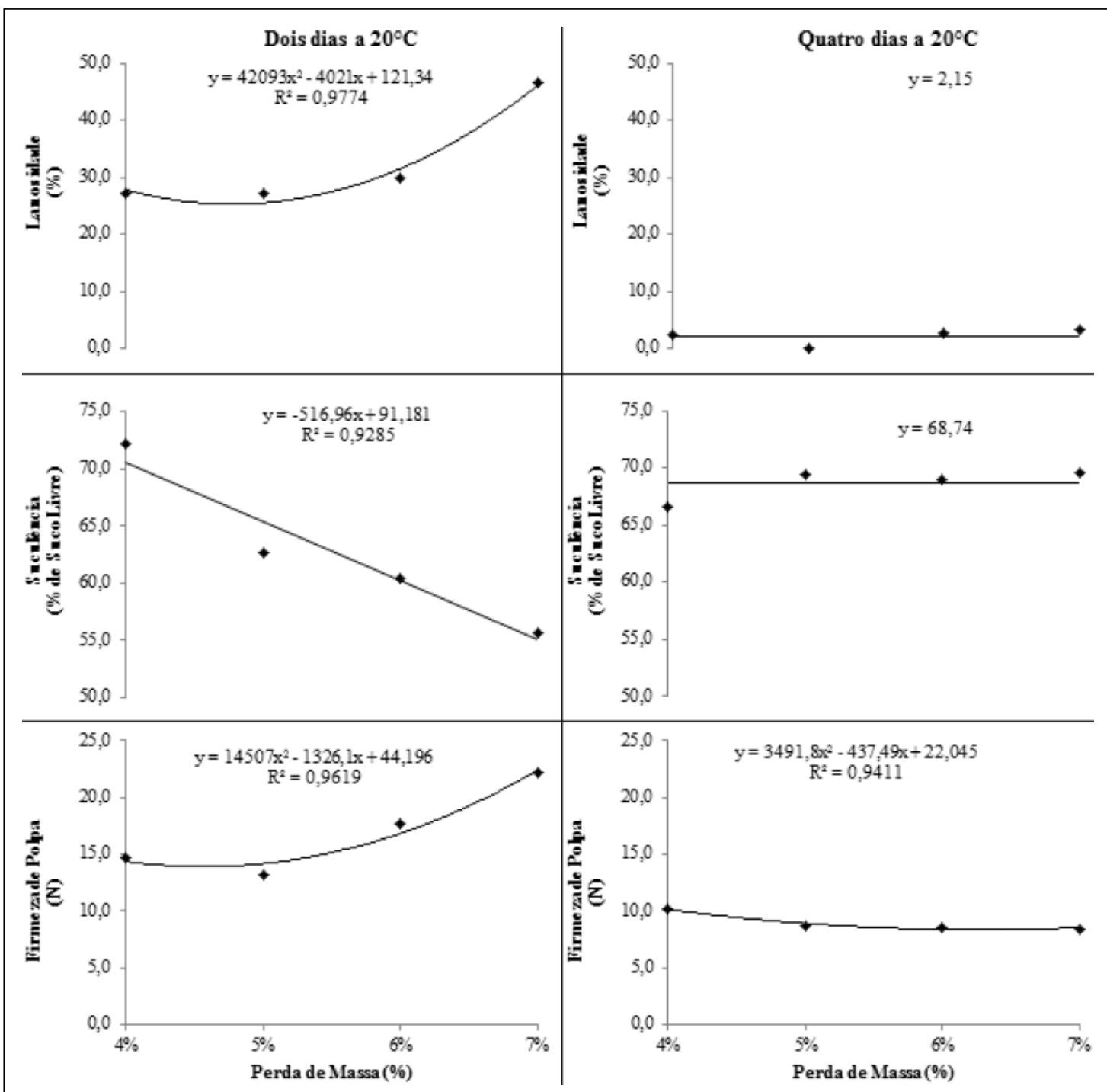

Figura 2 - Lanosidade, suculência e firmeza de polpa de pêssegos 'Eragil' após 21 dias em armazenamento refrigerado e indução de perda de massa fresca. UFSM-Santa Maria, 2011.

BRACKMANN (2002), após o armazenamento refrigerado, a exposição dos frutos à temperatura ambiente tende a restabelecer a suculência dos frutos, o que também foi observado neste trabalho. A percepção da lanosidade na análise subjetiva é através da presença de suco livre, podendo este ser mascarado, no presente trabalho, pela maior desidratação dos frutos em níveis maiores de perda de água.

A suculência dos frutos (Figura 2), parâmetro intimamente relacionado com a incidência de lanosidade, somente foi significativamente alterada pela perda de massa após dois dias de exposição a $20^{\circ} \mathrm{C}$, e teve relação inversa com esta, ou seja, quanto maior a perda de massa fresca induzida, menor a suculência. A suculência média dos frutos após quatro dias a $20^{\circ} \mathrm{C}$ foi $68,74 \%$, sem que houvesse diferença entre os níveis de perda de massa. Do mesmo modo que a incidência de lanosidade, os resultados obtidos de suculência não dão a certeza de que ocorrem devido à formação de "gel" com aprisionamento de água, ou se ocorrem devido à maior perda de água por transpiração dos frutos durante o armazenamento.

Dois dias após o final do armazenamento, o gráfico que representa a firmeza de polpa (Figura 2) teve o comportamento de uma parábola com concavidade voltada para cima. Os frutos submetidos a $7 \%$ de perda de massa mantiveram a firmeza de polpa em $22,16 \mathrm{~N}$, sendo 51,67 e $25 \%$ maior que aqueles 
submetidos a 4,5 e $6 \%$ de perda de massa, respectivamente. Da mesma forma, BRACKMANN et al. (2007), trabalhando com maçãs, verificaram maior firmeza de polpa com maior perda de massa induzida, até o nível de 3,2\%. Aos quatro dias de exposição dos frutos à temperatura ambiente, a firmeza de polpa também é explicada por uma função de segundo grau, no entanto, a variação é pequena, sendo o maior valor obtido com $4 \%$ de perda de massa. A firmeza de polpa sofreu redução do segundo ao quarto dia, pois, segundo LURIE \& CRISOSTO (2005), a reversão da lanosidade vem acompanhada de colapso e senescência dos tecidos, resultando em redução da firmeza de polpa, além da degradação natural das paredes, como observado na análise inicial.
A acidez titulável e sólidos solúveis totais (Figura 3) não apresentaram diferença estatística dois dias após o final do armazenamento, indicando que nesse período não há perda de qualidade dos frutos com a indução da perda de massa fresca. Aos quatro dias a $20^{\circ} \mathrm{C}$, a acidez titulável novamente não apresentou significância, porém, ocorreu um certo acúmulo, provavelmente pela degradação das paredes celulares. Os sólidos solúveis totais, aos quatro dias a $20^{\circ} \mathrm{C}$, tiveram comportamento linear, aumentando seu teor em $0,0,1,7$ e 7,2\% com o aumento da perda de massa de 4\% para 5, 6 e 7\%, respectivamente. Esses resultados concordam com os encontrados por BRACKMANN et al. (2007), trabalhando com maçãs 'Royal Gala', que não encontraram diferença na acidez

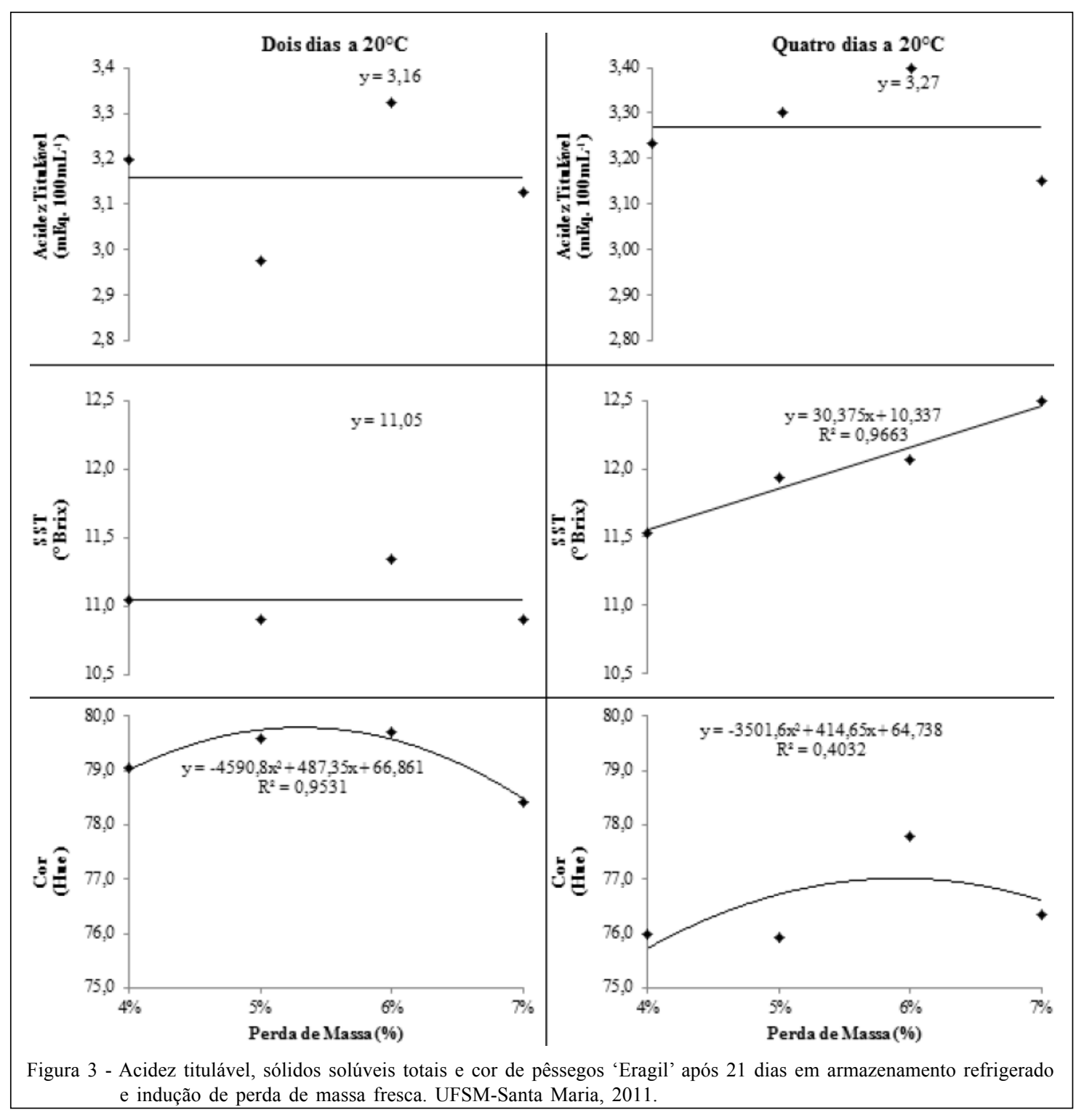

Ciência Rural, v.42, n.6, jun, 2012. 
titulável mas aumento dos sólidos solúveis totais com o aumento da perda de massa. A cor da epiderme dos frutos, tanto aos dois quanto aos quatro dias a $20^{\circ} \mathrm{C}$, é explicada por uma parábola com concavidade voltada para baixo, em que, $5,3 \%$ e $5,9 \%$, respectivamente, proporcionaram menor desenvolvimento da cor amarela, ou seja, encontravam-se menos maduros. Podese ainda observar que, dos dois aos quatro dias a $20^{\circ} \mathrm{C}$, houve desenvolvimento da cor amarela nos frutos.

A produção de etileno (Figura 4), tanto aos dois quanto os quatro dias a $20^{\circ} \mathrm{C}$, ajusta-se através de uma equação linear decrescente, ou seja, quanto maior a perda de massa menor a produção de etileno, concordando com BRACKMANN et al. (2007), que encontraram, em maçãs 'Royal Gala', que com o aumento da perda de massa, ocorre diminuição da produção de etileno. A declividade da reta é maior aos dois dias que aos quatro dias a $20^{\circ} \mathrm{C}$, mostrando que logo após o final do armazenamento o efeito da indução da perda de massa é mais pronunciado nos frutos. ALVES et al. (2010), em ameixas 'Laetitia', notaram que $1,5 \%$ de perda de massa não é suficiente para causar

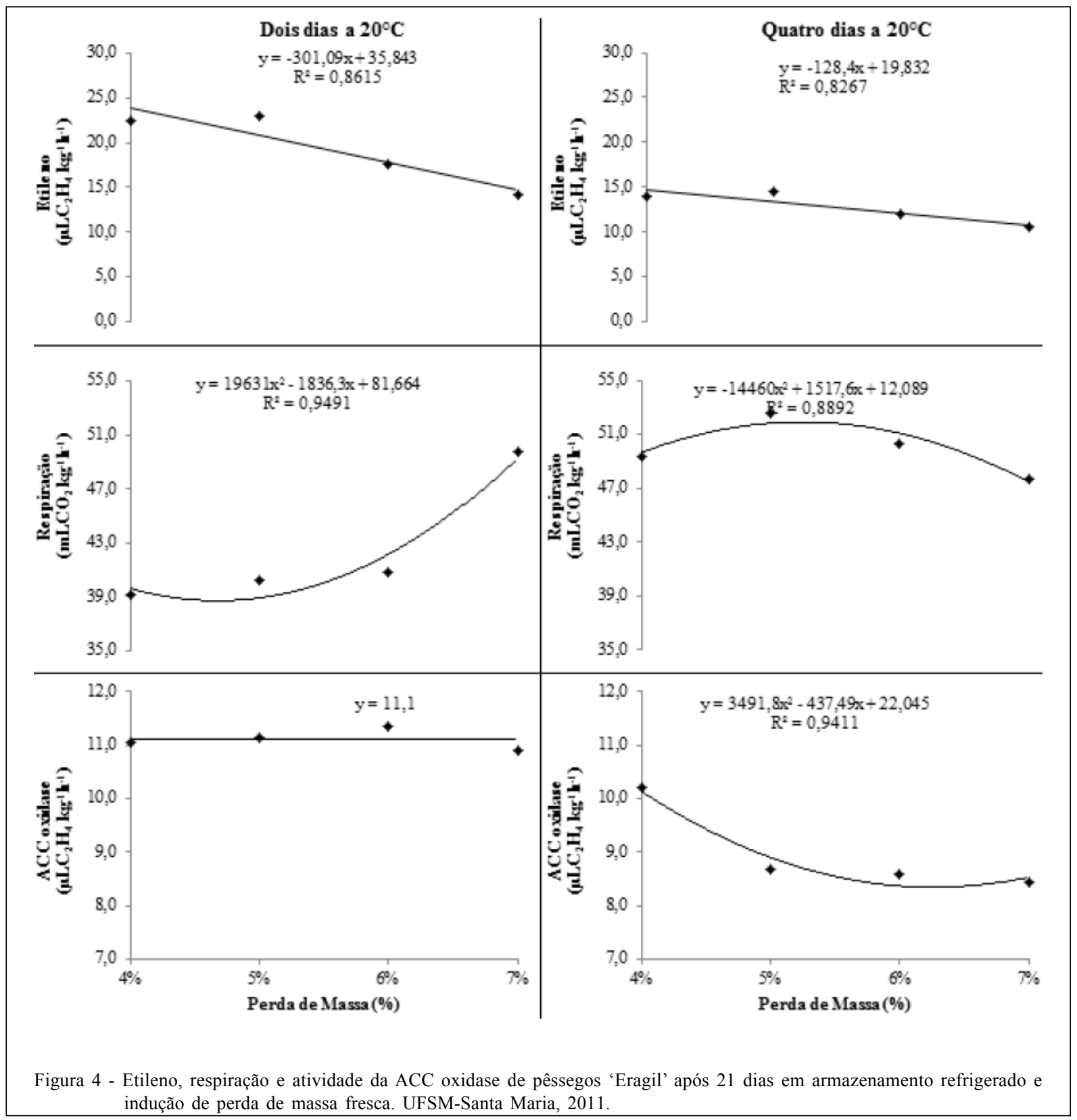

Ciência Rural, v.42, n.6, jun, 2012. 
diferença estatística na produção de etileno, o que justifica, de certa forma, a escolha dos níveis testados no presente trabalho.

A respiração dos frutos (Figura 4) apresentou diferentes comportamentos aos dois e quatro dias, sendo que, no primeiro caso, a curva que a explica é uma parábola com concavidade voltada para cima, e, no segundo caso, para baixo. Aos dois dias, a menor taxa respiratória ocorre com $4,7 \%$ de perda de massa, já aos quatro dias a $20^{\circ} \mathrm{C}, 5,2 \%$ de perda de massa proporciona a maior taxa respiratória. FINGER et al. (1995) observaram redução da produção de etileno e da taxa respiratória e antecipação do climatério com perda de massa de $5 \%$ em bananas. A atividade da enzima ACC oxidase (Figura 4), aos dois dias a $20^{\circ} \mathrm{C}$ não apresentou significância, ficando a média dos tratamentos em $11,1 \mu \mathrm{LC}_{2} \mathrm{H}_{2} \mathrm{~g}^{-1} \mathrm{~h}^{-1}$. Aos quatro dias de exposição à temperatura ambiente, a atividade da ACC oxidase é representada por uma curva com concavidade para cima, em que $6,3 \%$ de perda de massa proporciona a menor atividade.

\section{CONCLUSÃO}

Pêssegos 'Eragil' são susceptíveis à ocorrência de lanosidade após 21 dias de armazenamento refrigerado a $-0,5^{\circ} \mathrm{C}$, sendo este processo revertido a $20^{\circ} \mathrm{C}$.

O aumento na perda de massa fresca promove aumento na firmeza de polpa, lanosidade, sólidos solúveis totais e respiração e redução na suculência, produção de etileno e atividade da enzima ACC oxidase.

\section{REFERÊNCIAS}

ALVES, E.O. et al. Armazenamento refrigerado de ameixas 'Laetitia' com o uso de 1-MCP e indução de perda de massa fresca. Ciência Rural, v.40, n.1, p.30-36, 2010. Disponível em: <http:/ /www.scielo.br/scielo.php?script $=$ sci_arttext\&pid $=$ S0103$84782010000100006 \& \operatorname{lng}=\mathrm{pt} \& \mathrm{nrm}=\mathrm{iso}>$. Acesso em: 11 out. 2010. doi: 10.1590/ S0103-84782009005000251.

BARBOSA, W. et al. Advances in low-chilling peach breeding at Instituto Agronômico, São Paulo State, Brazil. Acta Horticulturae, v.872, p.147-150, 2010.

BRACKMANN, A. et al. Pré-resfriamento e absorção de etileno durante o armazenamento de pêssegos cv. Chiripá. Revista Brasileira de Armazenamento, v.26, p.12-15, 2001.

BRACKMANN, A et al. Indução da perda de massa fresca e ocorrência de distúrbios fisiológicos em maçãs 'Royal Gala' durante o armazenamento em atmosfera controlada. Revista Brasileira de Armazenamento, v.32, n.2, p.87-92, 2007.

BRACKMANN, A et al. Atmosfera refrigerada e controlada para pêssegos 'Eragil'. Ciência Rural, v.39, n.7, 2009. Disponível em: $<$ http://www.scielo.br/scielo.php?script=sci_arttext\&pid=S0103-
$84782009000700009 \& \operatorname{lng}=$ pt\&nrm=iso $>$. Acesso em: 29 jul. 2010. doi: 10.1590/S0103-84782009005000149.

FINGER, F.L. et al. Effects of water loss on respiration, ethylene production and ripening of banana fruit. Revista Brasileira de Fisiologia Vegetal. v.7, n.1, p.115-118, 1995.

IBGE. Produção agrícola municipal 2008. Rio de Janeiro, 2009. Disponível em: <http://www.ibge.gov.br/estadosat/ temas.php? sigla $=r$ s\&tema $=$ lavourapermanente2008 $>$. Acesso em: 29 jul. 2010.

LURIE, S.; CRISOSTO, C.H. Chilling injury in peach and nectarine. Postharvest Biology and Technology, v.37, p.195-208, 2005. Disponível em: <http:// pdn.sciencedirect.com.ez47.periodicos.capes.gov.br/ science?_ob=MiamiImageURL\&_cid $=271287 \&$ user $=923 \overline{8} 56 \&$ \& ii $=$ S $0925521405000888 \&$ \& chec $\bar{k}$ $=y \&$ origin $=$ search $\&$ zone $=$ rslt_list_item $\&$ coverDate $=2005$ -

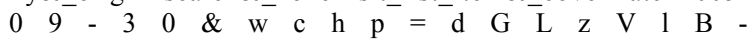
zSkzk\&md5=8d4448ab742d7715510b832826d6d8e0/1-s2.0S0925521405000888-main.pdf>. Acesso em: 03 fev. 2012. doi: $10.1016 /$ j.postharvbio.2005.04.012.

MADAIL, J.C.M.; RASEIRA, M.C.B. Aspectos da produção e mercado do pêssego no Brasil. Pelotas-RS: Embrapa Clima Temperado, 2008. (Circular Técnica, n.80). Disponível em: <http://www.cpact.embrapa.br/publicacoes $>$. Acesso em: 20 ago. 2009.

MAGUIRE, K.M., et al. Harvest date, cultivar, orchard and tree effects on water vapor permanence in apples. Journal of the American Society of Horticultural Science, v. 125, n.1, p.100-104, 2000.

NAVA, G.A.; BRACKMANN, A. Efeito do pré-resfriamento e da umidade relativa da câmara sobre a qualidade pós-colheita de pêssegos (Prunus persica (L.) Batsch), cv. 'Chiripá'. Revista Científica Rural, v.6, n.2, p.153-158, 2001.

NAVA, G.A.; BRACKMANN, A. Armazenamento de pêssegos (Prunus persica (1.) Batsch), cv. 'Chiripá', em atmosfera controlada. Revista Brasileira de Fruticultura, v.24, n.2, p.328-332, 2002. Disponível em: <http://www.scielo.br/ s cielo.ph p s cript =s ci_arttext\&pid=S $0100-$ $29452002000200011 \& \operatorname{lng}=\mathrm{en} \& \mathrm{nrm}=\mathrm{i}$ so\&tlng=pt>. Acesso em: 23 set. 2010. doi: 10.1590/S0100-29452002000200011.

OLIVEIRA, M.C. et al. Seleção de ameixeiras promissoras para a Serra da Mantiqueira. Revista Ceres, v.58, n.4, p.531535, 2011. Disponível em: <http://www.scielo.br/ scielo.php?script=sci_arttext\&pid=S0034$737 X 2011000400019 \& \operatorname{lng}=\mathrm{pt} \& \mathrm{nrm}=\mathrm{iso} \& \mathrm{t} \operatorname{lng}=\mathrm{pt}>$. Acesso em: 11 mar. 2011. doi: dx.doi.org/10.1590/S0034$737 \times 2011000400019$.

RHODES, M.J.C. The maturation and ripening of fruits. In: THIMANN, K.V. (Ed.). Senescence in plants. Boca Raton: CRC, 1980. p.157-205.

SCHWARZ, A. Relative humidity in cool stores: measurement, control and influence of discreet factors. Acta Horticulturae, v.2, n.368, p.687-692, 1994.

YANG, S.F.; PRATT, H.K. The physiology of ethylene in wounded plant tissue. In: KAHL, G. (Ed.). Biochemistry of wounded plant tissues. Berlin: Walter de Gruyter, 1978. p.596-622. 